\title{
Advancements in the Demonstration of High Thrust to Power Ion Engine Technology
}

\author{
Robert E. Thomas* and Michael J. Patterson ${ }^{\dagger}$ \\ NASA Glenn Research Center, Cleveland, $\mathrm{OH}, 44135$, USA \\ Jason A. Young ${ }^{\ddagger}$ and Mark W. Crofton ${ }^{\S}$ \\ The Aerospace Corporation, El Segundo, CA, 90245, USA \\ John E. Foster $₫$ \\ University of Michigan, Ann Arbor, MI, 48109, USA
}

\begin{abstract}
Gridded ion thrusters provide excellent thruster performance and have successfully been implemented on both geocentric and heliocentric missions. While ion thrusters have a substantial number of attractive technological attributes, they are often classified as inherently low thrust density devices. This manuscript details an ongoing collaborative effort among the NASA Glenn Research Center, the University of Michigan, and The Aerospace Corporation investigating ion engine design modifications for high thrust-density/high thrust-topower operation. Measurements were performed at The Aerospace Corporation in a 2.4-m diameter $\times$ 9.8-m long cryopumped vacuum chamber on an engineering model NEXT engine with a reduced interelectrode gap. The perveance, discharge losses, and far-field current density were characterized at operating conditions consistent with high thrust-to-power operation. The total voltage needed to achieve a given beam current was reduced by a factor of $10 \%$ with the reduced grid-gap optics, which is in close agreement with the Child Langmuir equation. The thrust loss correction factor ranged from 0.961 to 0.979 and was consistently higher than the predicted values. The discharge losses decreased with increasing beam current, with a minimum value of $150 \mathrm{~W} / \mathrm{A}$ at a beam current of $5.50 \mathrm{~A}$.
\end{abstract}

\section{Nomenclature}

$\begin{array}{ll}A_{b} & =\text { active beam area, } \mathrm{m}^{2} \\ d_{s} & =\text { screen aperture diameter, } \mathrm{m} \\ \mathrm{EM} & =\text { engineering model } \\ \mathrm{ETL} & =\text { extended throttle level } \\ F & =\text { thrust, } \mathrm{N} \\ f_{A} & =\text { thrust density, } \mathrm{N} / \mathrm{m}^{2} \\ g & =\text { gravitational constant, } \mathrm{m} / \mathrm{s}^{2} \\ I_{b} & =\text { beam current, } \mathrm{A} \\ I_{d} & =\text { discharge current, } \mathrm{A} \\ I_{s p} & =\text { specific impulse, } \mathrm{s} \\ j_{b} & =\text { beam current density, } \mathrm{A} / \mathrm{m}^{2} \\ l_{g} & =\text { interelectrode gap, } \mathrm{m} \\ m & =\text { ion mass, kg } \\ \mathrm{NEXT} & =\text { NASA's Evolutionary Xenon Thruster } \\ P_{i n} & =\text { input power, W } \\ \mathrm{PM} & =\text { prototype model }\end{array}$

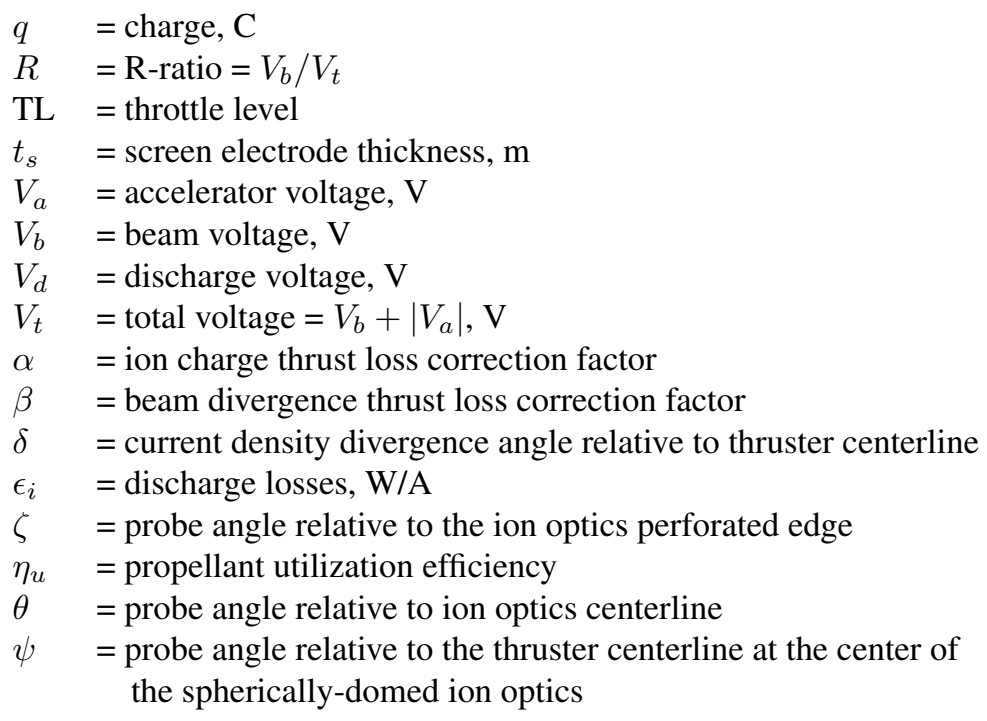

\footnotetext{
${ }^{*}$ Research Engineer, In-Space Propulsion Systems Branch, 21000 Brookpark Road/MS 301-3, AIAA Member.

${ }^{\dagger}$ Sr. Technologist, Propulsion Division, 21000 Brookpark Road/MS 301-3, AIAA Sr. Member.

${ }^{\ddagger}$ Member of Technical Staff, Space Materials Laboratory, M2-341, P.O. Box 92957, Los Angeles, CA 90009.

$\S$ Sr. Scientist, Space Materials Laboratory, M2-341, P.O. Box 92957, Los Angeles, CA 90009, AIAA Sr. Member.

${ }^{\top}$ Associate Professor, Department of Nuclear Engineering and Radiological Sciences, 1906 Cooley Building 2355 Bonisteel Boulevard, AIAA Member
} 


\section{Introduction}

Gridded ion thrusters provide excellent thruster performance and have successfully been implemented as primary propulsion on several NASA science missions. ${ }^{1,2}$ While ion thrusters have a substantial number of attractive technological attributes, there are many perceived shortcomings of the technology. However, what are generally characterized as limitations of ion thruster technology- e.g. system complexity and low thrust density- can be more accurately characterized as attributes that have been driven by mission requirements. ${ }^{3}$ For instance, ion thrusters are intentionally operated at low thrust densities for the purpose of achieving the extremely long lifetimes needed to support space science missions. It is possible, however, to operate these devices at thrust densities and absolute thrust levels equal to that of other high power devices that are more aligned with the requirements of earth-orbital needs.

NASA Glenn Research Center has successfully developed a number of ion propulsion systems. The NASAs Evolutionary Xenon Thruster (NEXT) project has developed next generation technologies that represent a significant advancement in technology beyond the state-of-the-art NASA Solar Technology Application Readiness thruster system. The NEXT engine incorporates a two-electrode ion optics design, has an active beam diameter of $36 \mathrm{~cm}$, and nominally operates with an input power range of $0.54-6.9 \mathrm{~kW}$. It has a maximum specific impulse of greater than 4170 seconds at a maximum thrust of greater than $236 \mathrm{mN}$, with peak efficiency in excess of 70\%. During the NEXT development process, refinements to the performance and dynamic throttling range have evolved. Table 1 shows the various throttle levels for NEXT. The green entries in the table are the NEXT planetary science throttle table levels, which will be referred to as the "standard" throttle levels (TLs). These throttle levels consist of 40 discrete operating points which are defined by a unique combination of the beam current and the beam power supply voltage. These throttle levels have been extensively studied and characterized over the past decade. ${ }^{4-6}$ Given the extraordinary lifetime capabilities of the NEXT engine established via both test ${ }^{7}$ and analyses ${ }^{8,9}$ for the standard throttle table, it has been determined that reducing the lifetime margin to enhance performance was a fair trade space to examine.

The yellow entries in Table 1 are the expanded throttle level (ETL) conditions, which do not require modification to the thruster or the power processor unit to implement. As such these new throttle set points could be advantageous for NASA planetary science applications, as well as earth- and cis-lunar science and commercial mission applications. The ETLs are consistent with high thrust-to-power operation, which focuses on sub- $3000 \mathrm{sec}$ specific impulse operation. The gray entries correspond to high-thrust density operation, with peak thruster input power levels of $14 \mathrm{~kW}$ and thrust levels of $460 \mathrm{mN}$, which are conditions consistent with the electrostatic capabilities of the ion optics. A significant amount of work has been completed on characterizing the extended throttle conditions. This work includes: high thrust-to-power testing ${ }^{10,11}$, performance and lifetime analyses ${ }^{12,13}$, and plume characterization. ${ }^{14}$ The blue entries in Table 1 correspond to operating conditions that were characterized during the current testing campaign, and are described in a later section.

\begin{tabular}{|c|c|c|c|c|c|c|c|c|c|c|c|c|c|}
\hline \multirow{2}{*}{$I_{b}, \mathrm{~A}$} & \multicolumn{13}{|c|}{$V_{b p s}, \mathrm{~V}$} \\
\hline & 1800 & 1567 & 1396 & 1179 & 1021 & 936 & 850 & 700 & 679 & 650 & 400 & 300 & 275 \\
\hline 7.04 & TL56 & TL55 & TL54 & TL53 & TL52 & TL51C & TL51B & TL51A & & & & & \\
\hline 5.80 & TL51 & TL50 & TL49 & TL48 & TL47 & TL46B & TL46A & TL46 & & & & & \\
\hline 5.50 & TL45G & TL45F & TL45E & TL45D & TL45C & TL45B & TL45A & TL45 (800) & & & & & \\
\hline 5.00 & TL44G & TL44F & TL44E & TL44D & TL44C & TL44B & TL44A & TL44 & TL44-1 & $50-540$ & & & \\
\hline 4.50 & TL43G & TL43F & TL43E & TL43D & TL43C & TL43B & TL43A & TL43 & & L43-660 - 4 & & & \\
\hline 4.00 & TL42G & TL42F & TL42E & TL42D & TL42C & TL42B & TL42A & TL42 & & & & & \\
\hline 3.52 & TL40 & TL39 & TL38 & TL37 & ETL3.52A & ETL3.52B & ETL3.52C & ETL3.52D & & ETL3.52 & $600-360$ & & \\
\hline 3.10 & TL36 & TL35 & TL34 & TL33 & ETL3.1A & ETL3.1B & ETL3.1C & ETL3.1D & ETL3.1E & & & & \\
\hline 2.70 & TL32 & TL31 & TL30 & TL29 & TL28 & ETL2.7A & ETL2.7B & ETL2.7C & ETL2.7D & ETL2.7E & TL28 (570) & & \\
\hline 2.35 & TL27 & TL26 & TL25 & TL24 & TL23 & ETL2.35A & ETL2.35B & ETL2.35C & ETL2.35D & ETL2.35E & & & \\
\hline 2.00 & TL22 & TL21 & TL20 & TL19 & $\overline{T L 18}$ & ETL2.0A & ETL2.0B & ETL2.0C & ETL2.0D & ETL2.0E & TL18 (480) & & \\
\hline 1.60 & TL17 & TL16 & TL15 & TL14 & TL13 & ETL1.6A & ETL1.6B & ETL1.6C & ETL1.6E & ETL1.6F & & & \\
\hline 1.20 & TL12 & TL11 & TL10 & TL09 & TL08 & TL07 & TL06 & & TL05 & TL04 & TL03 & TL02 & \\
\hline 1.00 & & & & & & & & & & & & & TL01 \\
\hline
\end{tabular}

Figure 1: The NEXT ion engine throttle table (green entries), the extended throttle levels (yellow entries), the high thrust-to-power levels (gray entries), and the throttle levels of this study (blue entries).

This manuscript details an ongoing collaborative effort among the NASA Glenn Research Center, the University of Michigan, and The Aerospace Corporation investigating ion engine design modifications for high thrust-to-power operation. The next section details performance estimates and a pathway to high performance engines. Data is then presented on a NEXT engine with modified ion optics and the conclusions and future work follows. 


\section{A. Motivation}

Ion engines have historically been relegated as inherently low-thrust density devices. It is instructive to investigate this claim further and define reasonable paths forward for achieving high thrust-to-power ratios. In doing so, it is useful to briefly review the pertinent analytical equations that define electrostatic engine performance. The electrostatic ion engine thrust density $f_{A}$ is given by:

$$
f_{A}=\alpha \beta \frac{I_{b}}{A_{b}} \sqrt{\frac{2 m V_{b}}{q}}
$$

where $I_{b}$ is the beam current, $V_{b}$ is the beam voltage, $A_{b}$ is the beam area, and $m / q$ is the ion mass to charge ratio. The thrust loss correction factor is the product of the doubly-charge ion thrust loss correction factor $\alpha$ and the plume divergence thrust loss correction factor $\beta$. The maximum beam current density is limited by the ion space charge in the gap between the screen and accelerator grids and can be expressed by a modified form of the 1-D Child-Langmuir equation, which for Xe propellant has the form:

$$
j_{b} \approx 4.771 \times 10^{-9} \frac{V_{t}^{3 / 2}}{\left(l_{g}+t_{s}\right)^{2}+\left(d_{s} / 2\right)^{2}}
$$

where $V_{t}$ is the total voltage, $l_{g}$ is the interelectrode gap, $t_{s}$ is the screen electrode thickness, and $d_{s}$ is the screen electrode aperture diameter. The current density is maximized by increasing the total voltage to the highest practical value while minimizing the ion optics geometric parameters to the lowest practical values. The specific impulse is given by:

$$
I_{s p}=\alpha \beta \eta_{u} \frac{1}{g} \sqrt{\frac{2 m V_{b}}{q}}
$$

where $\eta_{u}$ is the total propellant utilization efficiency and $g$ is the acceleration due to gravity. To maintain a specific impulse in the sub $3000 \mathrm{~s}$ range, the beam voltage is held below the nominal NEXT full power value. The total voltage is held constant to maximize ion beam extraction capability, which in practice is accomplished by increasing the accelerator grid voltage $V_{a}$. This has the net effect of decreasing the $R$-ratio, which is defined as:

$$
R \equiv \frac{V_{b}}{V_{t}}=\frac{V_{b}}{V_{b}+\left|V_{a}\right|}
$$

It has been found that operating with small values of $R$ can result in high-energy ion bombardment of the accelerator grid (potentially shortening grid life) as well as lead to an increase in the beam divergence loss. ${ }^{15}$ The testing described in this manuscript examines the relationship between $\beta$ and R-ratio. For high input power levels, $P_{i n}$ can be approximated as:

$$
P_{\text {in }} \approx I_{b}\left(V_{b}+\epsilon_{i}\right)
$$

Where the discharge loss $\epsilon_{i}$ is the discharge power divided by the beam current:

$$
\epsilon_{i}=\frac{V_{d} I_{d}}{I_{b}}
$$

The thrust-to-power ratio is for Xe propellant is then:

$$
\frac{F}{P_{i n}} \approx 1.650 \times 10^{-3} \alpha \beta \frac{V_{b}^{1 / 2}}{\left(V_{b}+\epsilon_{i}\right)}
$$

It can be seen that the thrust-to-power ratio is maximized when the thrust loss parameters, beam voltage, and discharge losses are minimized. While Eqn. 2 provides an upper limit on the beam current (thrust) that can be extracted from the optics, it should be noted that state-of-the-art engines typically operate far below the Child-Langmuir limit. For instance, the maximum beam current density of the NEXT standard throttle table is only about $20 \%$ of that which can be supported by the ion optics. Figure 2 shows the maximum thrust density that is anticipated for the NEXT ion optics as predicted from the beam current density from Eqn. 2 . The predicted maximum thrust density capability of the optics greatly exceeds the thrust densities associated with the standard throttle table at the total voltages of any given specific impulse.

Another design constraint that limits ion engine thrust density is the maximum supportable current. The NEXT engine utilizes a ring cusp magnetic circuit with a maximum anode current capability of 32 Amperes. At higher anode currents the discharge becomes highly resistive and unstable. In this instance the maximum thrust and thrust density are limited by the ability to produce additional ion current, and not the ability of the optics to extract additional ion current. 


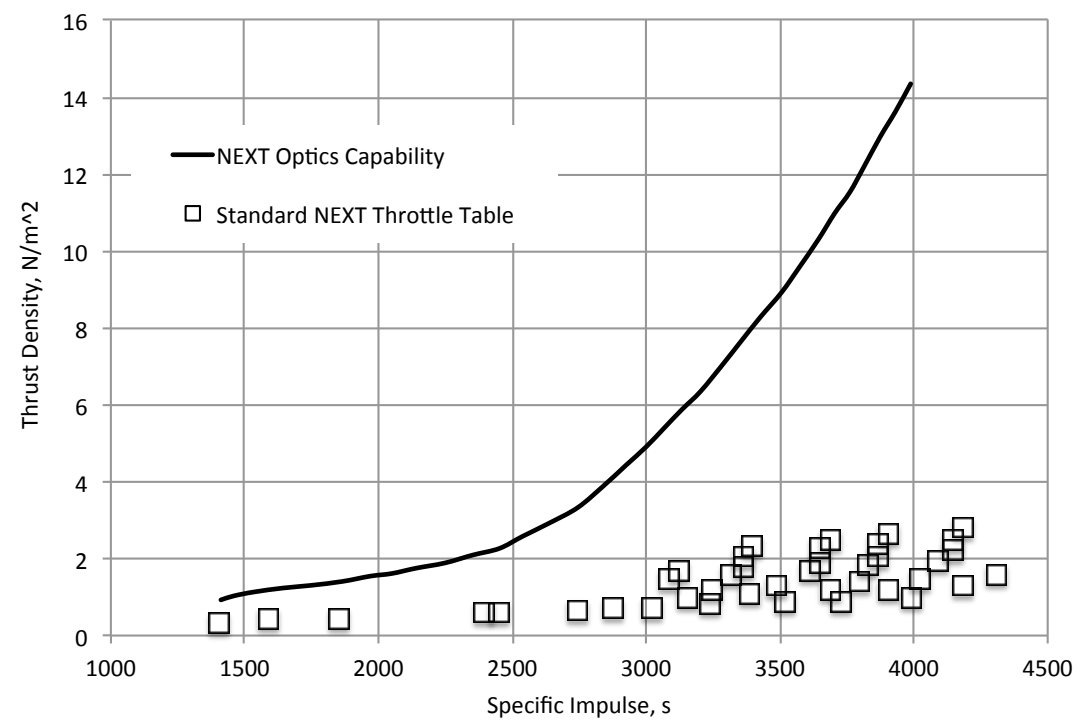

Figure 2: Comparison of NEXT performance with theorectical performance as predicted from the Child-Langmuir equation. Reproduced from Ref. [ 3].

This can be contrasted to the performance of a $28.7 \mathrm{~cm}$ beam diameter divergent field ion thruster that demonstrated a maximum anode current of 63 Amperes. ${ }^{16}$ The innovation of the ring-cusp magnet circuit design employed in SOA thrusters has brought about significant improvements (high electrical efficiency, uniform plasma production, reduced electrode voltages and enhanced life), however the degrees of improvement must be traded against ion production. The other major constraint associated with high thrust density performance is the service lifetime of the thruster. As previously mentioned, the standard throttle levels have been thoroughly characterized, with the bulk of the $51 \mathrm{khr}$ life test being run at TL 40 (3.52 A beam current), which is the harshest condition from the standpoint of accelerator grid wear. While it is clear that operating at elevated beam currents $(>3.52 \mathrm{~A})$ and accelerator voltages will lead to a decrease in thruster lifetime, this decrease needs to be quantified.

Reference 3 outlines the technology design paths for high-thrust density operation, which is illustrated in Fig. 3. One path (top) is the development of an annular geometry ion engine. The annular engine incorporates an annular discharge chamber, a magnetic circuit designed to circumvent ion source limiting, and high perveance flat graphite optics and is described in detail in Refs. [ 17-20]. The "conventional" engine pathway involves modification to a cylindical geometry such as the NEXT engine. These changes include a reduction in the interelectrode gap and/or a reduction of the screen grid thickness to increase the perveance, as well as changes in the discharge magnetic field topology. The testing described in this paper focuses on a reduction in the nominal NEXT interelectrode gap. Figure 4 shows the performance envelope for the $12.5 \mathrm{~kW}$ NASA Hall thruster, ${ }^{21}$ the BPT-4000, ${ }^{22}$ the NEXT engine, and the annular geometry ion engine. It can be seen that both ion engine technologies have demonstrated performance that encapsulates Hall thruster technologies, including operation in the sub-3000 sec specific impulse range.

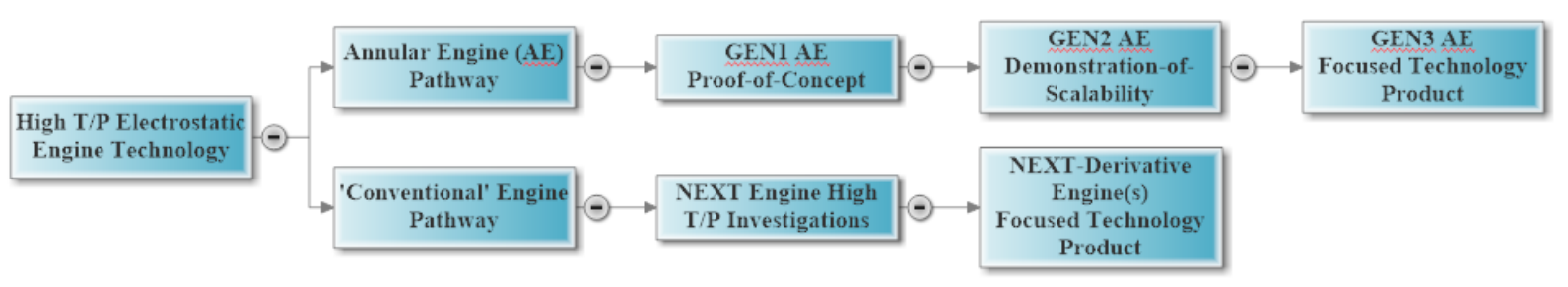

Figure 3: Development plan for high thrust density ion engines.

To summarize, there appears to be significant room for improvement in achieving high thrust density performance. The goals of the current research path with the NEXT engine are to:

1. Establish baseline performance for NEXT to go forward and modify the hardware (e.g. modify the optics to boost $\beta$, modify the discharge magnetic circuit to boost $\epsilon_{i}$ );

2. Ascertain the impact of grid gap change on perveance (to boost $\left.f_{A}\right)$, performance $\left(F / P_{i n}\right)$, and $\beta$;

3. Understand the sensitivities of $\beta$ and $\epsilon_{i}$ as functions of high beam currents and low R-ratio. 


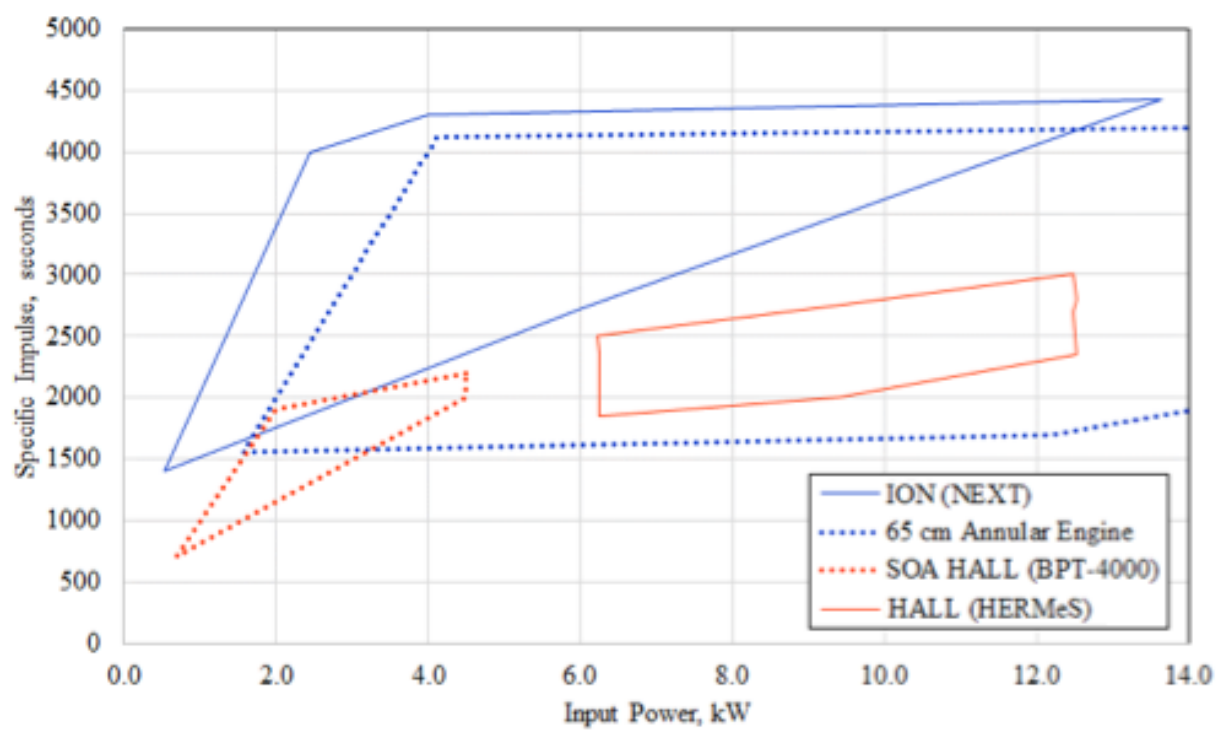

Figure 4: Comparison of electrostatic engine performance envelopes.

\section{Apparatus}

\section{A. Facility}

Measurements were performed at The Aerospace Corporation in a 2.4-m diameter $\times 9.8$-m long cryopumped vacuum chamber with the thruster oriented along the chamber centerline. The base pressure with no gas load was $1 \times 10^{-7}$ torr, with the residual gas being water vapor, air, and hydrocarbons. The chamber is lined with carbon composite sheets and flexible graphite to minimize the yield of sputtered material. Background pressure was measured by an ionization gauge located on the tank wall adjacent to the thruster. With an $800 \mathrm{~V}, 5.53 \mathrm{~A}$ beam the xenon pressure was $3.9 \times 10^{-6}$ torr. The effective pumping speed for this condition was $2.9 \times 10^{5} \mathrm{liter} / \mathrm{s}$.

\section{B. Test Article}

Five engineering model thrusters have been manufactured at Glenn Research Center and tested. Engineering model 4 (EM-4) was used for the tests reported in this paper. The thruster utilizes a partial-conic discharge chamber, a ring-cusp magnetic circuit, and $36 \mathrm{~cm}$ beam diameter ion optics. The discharge cathode assembly consists of a hollow cathode with an enclosed keeper electrode fabricated of graphite, and the neutralizer cathode assembly has a high degree of NSTAR heritage. The PM thruster design includes significant enhancements over the EM thruster design including: innovative coatings to increase emissivity for enhanced thermal margin, more uniform ion optics apertures with much shallower cusps, masked ion optics to reduce edge-hole erosion, and graphite discharge cathode keeper to mitigate keeper erosion. ${ }^{6}$ Detailed descriptions of the EM and PM designs can be found in Refs. 23 and 24 , respectively. The thruster was operated using commercially available power supplies and integrated recycle logic circuitry, allowing for thruster input powers up to $10 \mathrm{~kW}$ with beam power supply voltages up to $2000 \mathrm{~V}$. A calibrated, high-purity xenon feed system was used to deliver xenon propellant to the discharge cathode, neutralizer cathode, and discharge chamber main plenum through individual mass flow controllers.

\section{Plasma Diagnostics}

Measurements of the beam current density were made $273 \mathrm{~cm}$ from the accelerator electrode to determine beam divergence. The beam current density was measured with a conventional guard-ring planar probe using the rotating arm to scan in a grid-normal orientation at a constant distance (Fig. 5). The collector diameter was $1.27 \mathrm{~cm}$ and the guard ring outer diameter was $2.54 \mathrm{~cm}$. For the far-field scans the thruster was pivoted $12^{\circ}$ away from chamber centerline to expand the angular range, and the probe axis of rotation coincided with the center of curvature of the spherically-domed ion optics. 


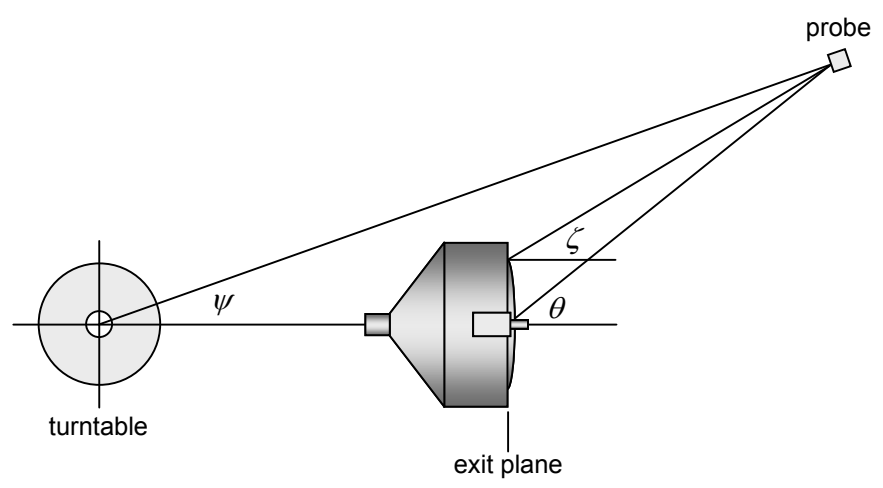

Figure 5: Schematic of plasma diagnostics for far-field current density measurements.

\section{Experimental Results}

Data were collected at the 26 operating conditions shown in Table 1 . This included, in part, five conditions from the standard throttle table, and four throttle levels that were modified ("MOD") by decreasing the beam voltage from the nominal value in order to increase the thrust density. Extended data sets were collected at beam currents of 3.52, 4.50, and 5.00 A. This was done to understand the influence of the R-ratio on $\beta$; this was accomplished by fixing the beam current and simultaneously decreasing $V_{b}$ and increasing the $V_{a}$. The peak thrust-to-power ratio occurs at ETL3.52-360; at this condition: $F / P_{\text {in }}=54 \mathrm{mN}$ and the specific impulse is 1826 seconds.

Table 1: Operating conditions for high thrust-to-power testing.

\begin{tabular}{cccccccc}
\hline TL & $J_{b}, \mathrm{~A}$ & $V_{b p s}, \mathrm{~V}$ & $V_{a}, \mathrm{~V}$ & $V_{t}, \mathrm{~V}$ & $\mathrm{R}-\mathrm{ratio}$ & $F / P, \mathrm{mN} / \mathrm{kW}$ & $I_{s p}, \mathrm{~s}$ \\
\hline 3 & 1.20 & 400 & -310 & 710 & 0.548 & 44 & 1855 \\
3MOD & 1.20 & 400 & -200 & 600 & 0.648 & 44 & 1861 \\
5 & 1.20 & 679 & -115 & 794 & 0.841 & 42 & 2447 \\
18 & 2.00 & 1021 & -175 & 1196 & 0.844 & 41 & 3237 \\
18MOD & 2.00 & 480 & -175 & 655 & 0.715 & 49 & 2194 \\
28 & 2.70 & 1021 & -175 & 1196 & 0.844 & 42 & 3117 \\
28MOD & 2.70 & 570 & -175 & 745 & 0.749 & 49 & 2321 \\
37 & 3.52 & 1179 & -200 & 1379 & 0.846 & 41 & 3386 \\
37MOD & 3.52 & 660 & -200 & 860 & 0.754 & 48 & 2504 \\
ETL 3.52-360 & 3.52 & 360 & -500 & 860 & 0.405 & 54 & 1826 \\
ETL 3.52-420 & 3.52 & 420 & -440 & 860 & 0.475 & 53 & 1986 \\
ETL 3.52-480 & 3.52 & 480 & -380 & 860 & 0.545 & 52 & 2131 \\
ETL 3.52-540 & 3.52 & 540 & -320 & 860 & 0.614 & 51 & 2269 \\
ETL 3.52-600 & 3.52 & 600 & -260 & 860 & 0.684 & 49 & 2407 \\
ETL 3.52-660 & 3.52 & 660 & -200 & 860 & 0.754 & 48 & 2531 \\
43 & 4.50 & 700 & -400 & 1100 & 0.625 & 48 & 2633 \\
43-420 & 4.50 & 420 & -560 & 980 & 0.416 & 53 & 2010 \\
43-480 & 4.50 & 480 & -520 & 1000 & 0.468 & 52 & 2158 \\
43-540 & 4.50 & 540 & -480 & 1020 & 0.518 & 51 & 2298 \\
43-600 & 4.50 & 600 & -440 & 1040 & 0.565 & 50 & 2432 \\
43-660 & 4.50 & 660 & -400 & 1060 & 0.611 & 49 & 2555 \\
44 & 5.00 & 700 & -500 & 1200 & 0.572 & 48 & 2671 \\
44-540 & 5.00 & 540 & -580 & 1120 & 0.471 & 51 & 2336 \\
44-600 & 5.00 & 600 & -540 & 1140 & 0.515 & 50 & 2471 \\
44-660 & 5.00 & 660 & -500 & 1160 & 0.559 & 49 & 2587 \\
45-800 & 5.53 & 800 & -540 & 1340 & 0.588 & 46 & 2873 \\
\hline & & & & & & &
\end{tabular}

The discharge losses as a function of the beam current is shown in Fig. 6. As the beam current is increased the xenon ionization rate also increases; it has been shown that this leads to a decrease in the discharge losses. ${ }^{25}$ From Eqn. 7 the decrease in discharge losses as the beam current is increased is beneficial from the standpoint of optimizing the thrust-to-power ratio. 


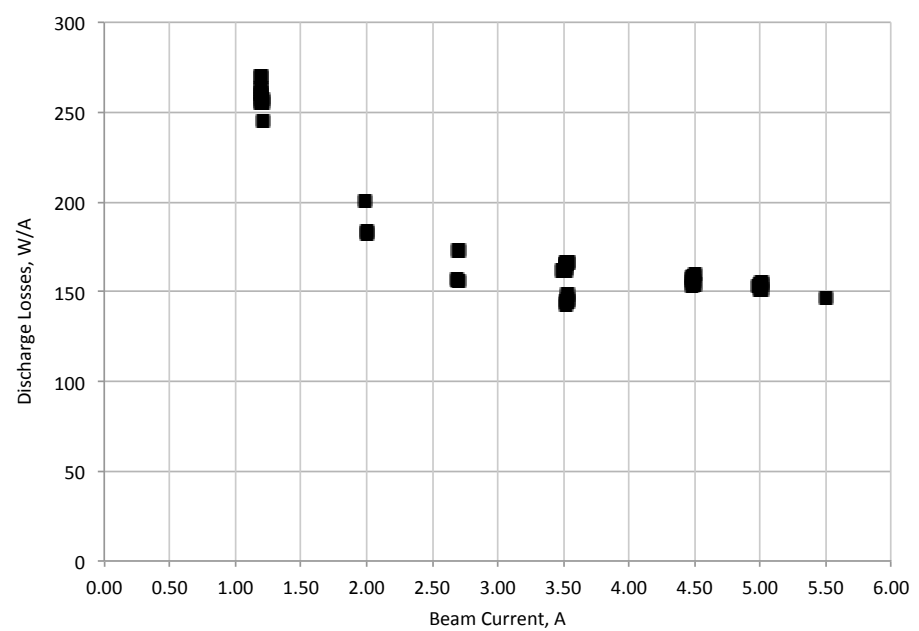

Figure 6: Discharge losses vs. beam current.

The impingement-limited total voltage is a measure of the current extraction capability of the ion optics and is determined from plots of accelerator current as a function of total voltage (Fig. 7). The perveance limited voltage is defined as the voltage where the slope is $-0.02 \mathrm{~mA} / \mathrm{V}$. The measured perveance for both nominal and re-gapped electrodes is shown in Fig. 8. For a fixed beam current, the total voltage was expected to decrease according to Eqn. 8 , which predicts that reducing the grid gap by $21 \%$ will lead to an $11 \%$ decrease in the total voltage. It should be noted that the grip gap is not constant along the span of the electrodes; an average cold gap value was used for the calculations. It can be seen that the simplified 1-D Child Langmuir equation provides a reasonable estimate of the total voltage, and is within $5 \%$ of the experimental values.

$$
\frac{V_{t, r e-g a p}}{V_{t, n o m}}=\left[\frac{\left(l_{g, r e-g a p}+t_{s}\right)^{2}+\left(d_{s} / 2\right)^{2}}{\left(l_{g, n o m}+t_{s}\right)^{2}+\left(d_{s} / 2\right)^{2}}\right]^{2 / 3}
$$

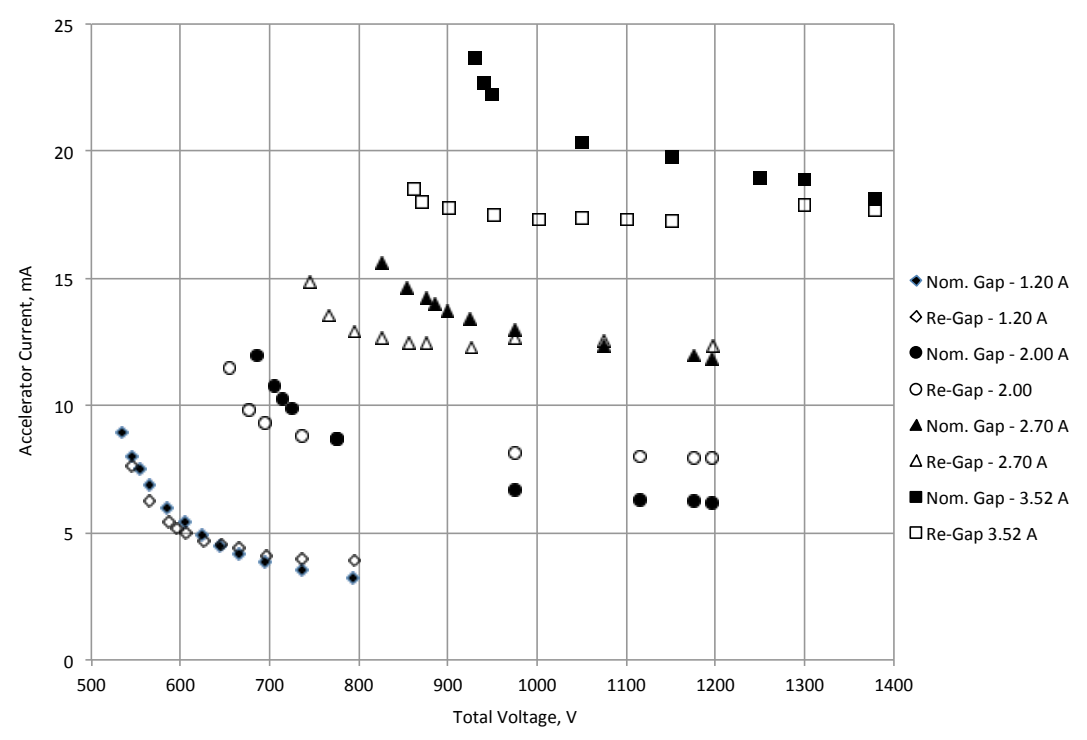

Figure 7: Accelerator current vs. total voltage.

Representative current density traces as measured by the planar probe are shown in Fig. 9. The beam divergence thrust-loss factor is experimentally found using the methodology described by Pollard in Ref. 26, and is calculated using Eqn. 9. The integrand in the numerator is the product of the axial component of beam current density $j_{b} \cos (\delta)$ and the area weighting factor $\sin (\psi) \mathrm{d} \psi$. The scan range was from $\psi=0^{\circ}$ to $29.5^{\circ}$ in $0.5^{\circ}$ steps, i.e. $\delta=00^{\circ}$ to $-33.0^{\circ}$. For integrating Eqn. (9), the data are extrapolated to reduce the truncation error by assuming an exponential fall-off in $j_{b}$ vs. $\psi$ for angles between $29.5^{\circ}$ and $45^{\circ}$ (Fig. 9). 


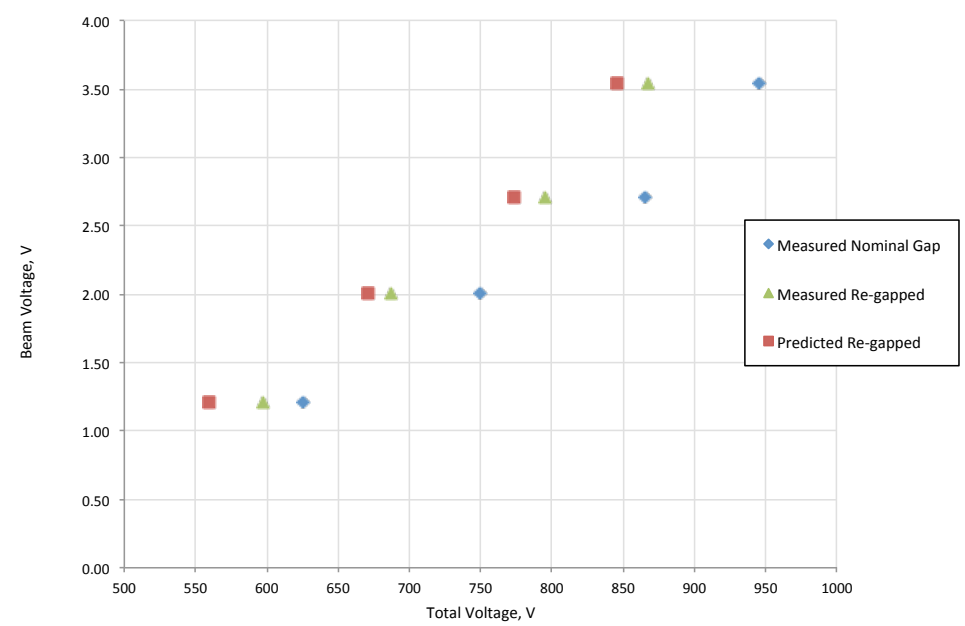

Figure 8: Beam current vs. total voltage for reduced grid gap optics.

$$
\beta=\frac{\int_{0}^{-45^{\circ}} j_{b} \cos (\delta) \sin (\psi) \mathrm{d} \psi}{\int_{0}^{-45^{\circ}} j_{b} \sin (\psi) \mathrm{d} \psi}
$$

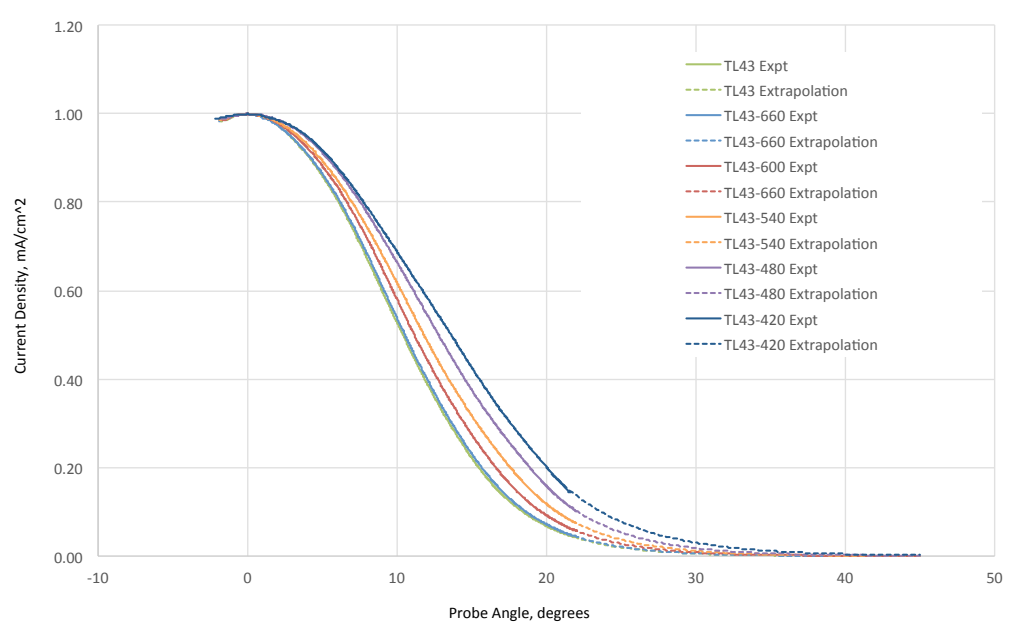

Figure 9: Beam current density vs. probe angle for the re-gapped EM-4 engine.

The thrust loss divergence factors calculated from the current density measurements are shown in Fig. 10 for nineteen different operating conditions. As expected, the beam divergence increases with decreasing R-ratio, which is consistent with prior ion optic studies. ${ }^{27}$ An empirical equation for calculating $\beta$ was obtianed from a curve fit of experimental data in Ref. [ 10]:

$$
\beta_{f i t}=\beta^{*}-0.1470+0.8440(R)-20.675(R)^{2}+2.3661(R)^{3}-1.0167(R)^{4}
$$

The $\beta^{*}$ term is a normalization constant that takes into account the: 1) accelerator-to- screen grid aperture diameter ratio; 2) accelerator grid thickness-to-screen grid aperture diameter ratio, and 3) the grid gap-to-screen grid aperture diameter ratio. It can be seen from Fig. 10 that the predicted $\beta$ accurately captures the trends in beam divergence, and is generally in close agreement to the experimental values. The divergence data for throttle levels 5 and 37 are compared to the PM1R data that Pollard collected in Table 2. The EM-4 $\beta$ value is within the error bar measurement at the PM1R measurement at TL 5, and is 1\% less than the PM1R value at TL37, which illustrates that re-gapping the optics did not lead to a significant increase in the beam divergence for a given operating condition. The measured 
values are consistent with projected performance of the thruster, and Eqn. 10 provides a reasonable estimate for the operating conditions tested, and will continue to be used for future estimations of performance.

Table 2: Comparison of experimental $\beta$ values for EM-4 and PM1R.

\begin{tabular}{ccc}
\hline TL & $\beta$ (PM1R) & $\beta$ (Re-gapped EM-4) \\
\hline 5 & 0.977 & 0.972 \\
37 & 0.974 & 0.965 \\
\hline
\end{tabular}

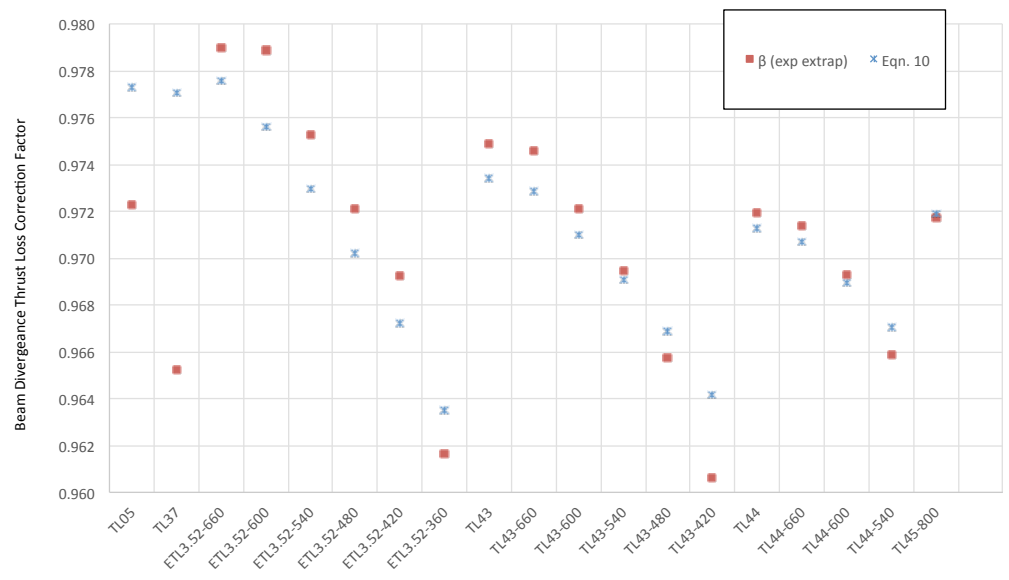

Figure 10: Divergence Loss Correction Factor for re-gapped EM-4 Engine.

\section{Summary \& Future Work}

Measurements were performed on an engineering model NEXT engine with a modified ion optics geometry in order to investigate the influence of electrode gap on beam divergence and discharge losses. The perveance, discharge losses, and far-field ion density were characterized at operating conditions consistent with high-thrust-to-power ratio operation at beam currents in the range of 1.20-5.53 A. The total voltage needed to achieve a fixed beam current was reduced by a factor of $10 \%$ with the reduced grid-gap optics, which is in close agreement with the 1-D Child Langmuir equation. The thrust loss correction factor, as measured using a planar Faraday probe, ranged from 0.961 to 0.979 and was modelled accurately using a previously developed polynomial fit. The discharge losses decreased with increasing beam current, with a minimum value of $150 \mathrm{~W} / \mathrm{A}$ at a beam current of $5.50 \mathrm{~A}$.

Two paths have been discussed that will provided near term opportunities for high thrust density and high thrust-topower ion engine operation: 1) modifying conventional cylindrical geometry ion engines by incorporating advanced design ion optics and/or divergent field magnetic field topologies; and the 2) development of annular ion engine geometries. The latter route is further discussed in a companion paper. The results presented in this paper are the first step in the investigation of high thrust density operation by making straight-forward alterations to the NEXT engine. The preliminary results are encouraging, and it should be noted that the test was not limited the capability of the ion optics, but by the discharge and accelerator power supply that were used for the test. A $20 \mathrm{~kW}$ power console with higher output discharge and accelerator capabilities has been assembled and will be used for future tests.

\section{Acknowledgments}

The authors acknowledge Mr. Kevin McCormick of NASA Glenn Research Center for work on thruster design, fabrication, and assembly. This work was supported under the Glenn Research Center Center Innovation Fund program sponsored by NASA's Office of Chief Technologist, and The Aerospace Corporation's Independent Research and Development Plan. 


\section{References}

${ }^{1}$ Polk, J., Kakuda, R., Anderson, J., and Brophy, J., "Performance of the NSTAR Ion Propulsion System on the Deep Space One Mission," $39^{\text {th }}$ AIAA Aerospace Sciences Meeting \& Exhibit, Reno, NV, Jan. 8-11 2001, AIAA-2001-0965.

${ }^{2}$ Brophy, J., Garner, C., Nakazono, B., Marcucci, M., Henry, M., and Noon, D., "The Ion Propulsion System for Dawn," $39^{t h}$ AIAA/ASME/SAE/ASEE Joint Propulsion Conference and Exhibit, Huntsville, AL, July 20-23, 2003, AIAA-2003-4542.

${ }^{3}$ Patterson, M. J., "Development Status of High-Thrust Density Electrostatic Engines," 50 ${ }^{\text {th }}$ AIAA/ASME/SAE/ASEE Joint Propulsion Conference and Exhibit, Cleveland, OH, July 28-30, 2014, AIAA-2014-3422.

${ }^{4}$ Soulas, G. C., Domonkos, M. T., and Patterson, M. J., "Performance Evaluation of the NEXT Ion Engine," 39 ${ }^{\text {th }}$ AIAA/ASME/SAE/ASEE Joint Propulsion Conference and Exhibit, Huntsville, AL, July 20-23, 2003, AIAA-2003-5278.

${ }^{5}$ Soulas, G. C. and Patterson, M. J., "NEXT Ion Thruster Performance Dispersion Analyses," $43^{\text {rd }}$ AIAA/ASME/SAE/ASEE Joint Propulsion Conference and Exhibit, Cincinnati, OH, July 8-11, 2007, AIAA-2007-5213.

${ }^{6}$ Herman, D. A., Soulas, G. C., and Patterson, M. J., "Performance Evaluation of the Prototype-Model NEXT Ion Thruster," $43^{r d}$ AIAA/ASME/SAE/ASEE Joint Propulsion Conference and Exhibit, Cincinnati, OH, July 8-11, 2007, AIAA-2007-5213.

${ }^{7}$ Shastry, R., Herman, D. A., Soulas, G. C., , and Patterson, M. J., "End-of-Test Performance and Wear Characterization of NASAs Evolutionary Xenon Thruster (NEXT) Long-Duration Test," $50^{\text {th }}$ AIAA/ASME/SAE/ASEE Joint Propulsion Conference and Exhibit, Cleveland, OH, July 28-30, 2014, AIAA-2014-3617.

${ }^{8}$ Van Noord, J., "Lifetime Assessment of the NEXT Ion Thruster," $43^{\text {rd }}$ AIAA/ASME/SAE/ASEE Joint Propulsion Conference and Exhibit, Cincinnati, OH, July 8-11, 2007, AIAA-2007-5274.

${ }^{9}$ Van Noord, J. and Herman, D. A., "Lifetime Assessment of the NEXT Ion Thruster," $44^{\text {th }}$ AIAA/ASME/SAE/ASEE Joint Propulsion Conference and Exhibit, Hartford, CT, July 21-23, 2008, AIAA-2008-4526.

${ }^{10}$ Patterson, M. J., "NEXT Study of Thruster Extended Performance (NEXT STEP)," $42^{\text {nd }}$ AIAA/ASME/SAE/ASEE Joint Propulsion Conference and Exhibit, Sacramento, CA, July 9-12, 2006, AIAA-2006-4664.

${ }^{11}$ Patterson, M. J., Soulas, G. C., Young, J. A., and Crofton, M. W., "Expanded Throttling Capabilities of the NEXT Thruster," $49^{\text {th }}$ AIAA/ASME/SAE/ASEE Joint Propulsion Conference and Exhibit, San Jose, CA, July 14-17, 2013, AIAA-2013-3891.

${ }^{12}$ Patterson, M. J., "NEXT Study of Thruster Extended Performance II (NEXT STEP II)," $44^{\text {th }}$ AIAA/ASME/SAE/ASEE Joint Propulsion Conference and Exhibit, Hartford, CT, July 21-23, 2008, AIAA-2008-4808.

${ }^{13}$ Patterson, M. J., Pinero, L., and Sovey, J. S., "Near-Term High Power Ion Propulsion Options for Earth-Orbital Applications," $45^{t h}$ AIAA/ASME/SAE/ASEE Joint Propulsion Conference and Exhibit, Denver, CO, August 2-5, 2009, AIAA-2009-4819.

${ }^{14}$ Young, J. A., Crofton, M. W., Diamant, K. D., and Patterson, M. J., "Plume Characterization of the NEXT Thruster Under Extended Throttle Conditions," 49th AIAA/ASME/SAE/ASEE Joint Propulsion Conference and Exhibit, San Jose, CA, July 14-17, 2013, AIAA-2013-4111.

${ }^{15}$ Aston, G. and Kaufman, H., "The Ion-Optics of a Two-Grid Electron-Bombardment Thruster," AIAA International Electric Propulsion Conference, Key Biscayne, FL, November 14 - 17, 1976, AIAA-P-76-1029.

${ }^{16}$ Patterson, M. J. and Rawlin, V. K., "Performance of $10 \mathrm{~kW}$ Class Xenon Ion Thrusters," $24^{\text {th }}$ AIAA/ASME/SAE/ASEE Joint Propulsion Conference and Exhibit, Boston, MA, July 11-13, 1988, AIAA-1988-2914.

${ }^{17}$ Patterson, M. J., "Next Generation Electric Propulsion Thrusters," $47^{\text {th }}$ AIAA/ASME/SAE/ASEE Joint Propulsion Conference and Exhibit, San Diego, CA, July 31 - August 3, 2011, AIAA-2011-5812.

${ }^{18}$ Patterson, M. J., Herman, D. A., Shastry, R., and Van Noord, J., "Annular-Geometry Ion Engine: Concept, Development Status, and Preliminary Performance," $48^{\text {th }}$ AIAA/ASME/SAE/ASEE Joint Propulsion Conference and Exhibit, Atlanta, GA, July 30 - August 1, 2012, AIAA2012-3798.

${ }^{19}$ Shastry, R., Patterson, M. J., Herman, D. A., and Foster, J. E., "Current Density Measurements of an Annular Geometry Ion Engine," $48^{t h}$ AIAA/ASME/SAE/ASEE Joint Propulsion Conference and Exhibit, Atlanta, GA, July 30 - August 1, 2012, AIAA-2012-4186.

${ }^{20}$ Patterson, M. J., Foster, J. E., Young, J. A., and Crofton, M. W., "Annular Engine Development Status," $49^{\text {th }}$ AIAA/ASME/SAE/ASEE Joint Propulsion Conference and Exhibit, San Jose, CA, July 14-17, 2013, AIAA-2013-3892.

${ }^{21}$ Kamhawi, H., Huang, W., Haag, T., Yim, J., Chang, L., Clayman, L., Herman, D. A., Shastry, R., Thomas, R., Griffith, C., Myers, J., Williams, G., Mikellides, I. G., Hofer, R. R., Polk, J. E., and Goebel, D., "Overview of the Development of the Solar Electric Propulsion Technology Demonstration Mission 12.5-kW Hall Thruster," 50 th AIAA/ASME/SAE/ASEE Joint Propulsion Conference and Exhibit, Cleveland, OH, July 28 30, 2014, AIAA-2014-3898.

${ }^{22}$ Welander, B., Carpenter, C., de Grys, K., Hofer, R. R., and Randolph, T. M., "Life and Operating Range Extension of the BPT-4000 Qualification Model Hall Thruster," 42 ${ }^{\text {nd }}$ AIAA/ASME/SAE/ASEE Joint Propulsion Conference and Exhibit, Sacramento, CA, July 9 - 12, 2006, AIAA-2006-5263.

${ }^{23}$ Patterson, M. J., Foster, J. E., Haag, T. W., Rawlin, V. K., Soulas, G. C., and Roman, R. F., "NEXT: NASA's Evolutionary Xenon Thruster," $38^{\text {th }}$ AIAA/ASME/SAE/ASEE Joint Propulsion Conference and Exhibit, Indianapolis, IN, July 7 - 10, 2002, AIAA-2002-3832.

${ }^{24}$ Hoskins, W. A., Wilson, F. C., Polaha, J., Talerico, L., Patterson, M. J., Soulas, G. C., and Sovey, J., "Development of a Prototype Model Ion Thruster for the NEXT System," 40 ${ }^{\text {th }}$ AIAA/ASME/SAE/ASEE Joint Propulsion Conference and Exhibit, Fort Lauderdale, FL, July 11 - 14, 2004 , AIAA-2004-4111.

${ }^{25}$ Goebel, D. M., Wirz, R. E., and Katz, I., “Analytical Ion Thruster Discharge Performance Model,” Journal of Propulsion and Power, Vol. 23, No. 5, 2007, pp. 1055-1067.

${ }^{26}$ Pollard, J. E., Diamant, K. D., Crofton, M. W., Patterson, M. J., and Soulas, G. C., "Spatially Resolved Beam Current and Charge-State Distributions for the NEXT Ion Engine," $46^{\text {th }}$ AIAA/ASME/SAE/ASEE Joint Propulsion Conference and Exhibit, Nashville, TN, July 25 - 28, 2010 , AIAA-2010-6779.

${ }^{27}$ Aston, G., Kaufman, H., and Wilbur, P., "Ion Beam Divergence Characteristics of Two-Grid Accelerator Systems," AIAA Journal, Vol. 16, No. 5, 1978, pp. 516-524. 